\title{
Should we be frightened of bracken? A review of the evidence
}

\author{
Deborah Wilson, Liam J Donaldson, Ovnair Sepai
}

\begin{abstract}
Objective-To assess the risk to human health of the plant bracken (Pteridium $s p)$.

Design-An evaluation of studies of human and animal populations exposed to bracken, together with a review of expert reports and advice to the public.

Main results-Bracken induced disease has been demonstrated in animals in both laboratory and field studies. Depending on the species, diseases in animals associated with the plant have included: cancers of the alimentary and urogenital tract, lung and breast; haematuria; retinal degeneration; and, thiamine deficiency. Potential exposure of human populations is through: food either directly (people in some parts of the world eat bracken as a traditional dish) or indirectly by consuming animals fed on bracken; milk; water; inhalation and ingestion of spores; and insect vectors. Four studies of human populations (two analytical and two observational) failed to assess adequately confounding factors and other sources of bias, so that conclusions about a risk to human health from bracken cannot firmly be drawn. Establishing exposure is also extremely difficult in populations (such as the United Kingdom) where direct consumption of bracken is rare.
\end{abstract}

Conclusion-Bracken is a common plant worldwide. It is toxic to many animal species and to several organ systems. There is no tumour (or other disease) that is pathognomic of exposure in animals, though cancers of the alimentary and urogenital tract seem to be the most commonly associated. It is not possible to extrapolate from animal models to humans. Studies of human populations, do not establish a clear risk of bracken to human health, largely because of methodological problems. Testing the evidence against traditional criteria of causality only fulfils the criterion of biological plausibility. Despite this, current public information implies a serious risk to human health from bracken, and increasing media coverage of the subject is likely to lead to greater public concern. Further epidemiological studies are required. (F Epidemiol Community Health 1998;52:812-817)

Should walkers and agricultural workers be warned to avoid bracken covered areas in the sporing season or wear facemask protection? Is there good evidence that bracken damages human health? Headlines such as "Curse of the killer bracken" and a warning on the British Broadcasting Corporation's Countryfile programme ${ }^{2}$ to avoid bracken or use masks during the sporing season are capable of causing considerable public alarm about this issue. The Bracken Advisory Commission's leaflet on risks associated with bracken ${ }^{3}$ provides helpful advice about avoiding sheep ticks in bracken, but also states that "it is highly advisable to keep well away from it. When it is sporing, avoid being downwind of it," and comments on "the cancer threat posed by inhaling bracken spores."

In the light of this range of practical advice to the public that implies that there are dangers, is there evidence that bracken presents a threat to human health?

\section{Background}

The fern, bracken (Pteridium $s p$ ) is an ancient plant that grows in abundance worldwide except in very cold or dry conditions. ${ }^{4}$ Many interest groups have focused their attention on bracken, either because of the belief that as a plant mass it is interesting or because of concerns about its ability to have deleterious effects on animals, human activities and even, human health. An International Bracken Group was established in 1985. Table 1 shows the potential range of interest in bracken by expert bodies.

The area of land covered by bracken is difficult to assess and calculations are often imprecise. Estimates of bracken encroachment are also problematic. Aerial photography and land survey are the most commonly used methods. Bracken invades land when the conditions are favourable, typically land that is underused or woodlands in decline. Such conditions may be because of: replacement of cattle by sheep; overgrazing; woodland clearance; drainage of moorland and rough pasture; cessation of bracken cutting; and, farming "set-aside" policies. Global warming may also accelerate encroachment of bracken onto highlands:

Table 1 Potential range of expert interests in bracken

Biological sciences - zoology, botany, genetics, taxonomy, toxicity, carcinogenicity, spore studies

Earth sciences - geography, geology, climate change, soil studies

Environmental health - risk to animals and humans Social sciences - change in land use, economic and cultural changes, cultural history

Rural sciences - agricultural systems, forests and bracken, agricultural economics, land use, bracken control Medical and veterinary services

Government - Ministry of Agriculture Fisheries and Food (MAFF), Department of Health, Department of the

Environment

Health and Safety Executive 


\section{Table 2 Diseases in animals associated with bracken}

Induced thiamine deficiency in horses and pigs $^{18}$

Acute poisoning (causing bone marrow dysplasia) and enzootic haematuria in cattle and sheep ${ }^{19}$ Cancers of urogenital and alimentary tract in cattle ${ }^{20}$

Cancers of urogenital and alimen
Bladder tumours in guinea pigs ${ }^{11}$

Progressive retinal degeneration (bright blindness) in sheep ${ }^{22}$

Ileal adenocarcinomas in rats fed on bracken ${ }^{16}$

Interaction of papillomavirus and bracken consumption associated with cancer of the alimentary canal in cattle e $^{23}$

Bracken as an important habitat for sheep ticks (Ixodes ricinus) in the UK

Bracken may act as an immunosuppressant that activates latent papillomavirus causing premalignant bladder lesions in cows, then acts as co-carcinogen with the virus to progress to cancer $^{24}$

$100 \%$ of mice fed on bracken fern for three months developed pulmonary tumours compared with $7 \%$ of controls ${ }^{25}$

$37 \%$ of mice fed on milk from bracken fed cows developed pulmonary tumours and $27 \%$ of female mice developed mammary tumours, compared with $7 \%$ and $0 \%$ in controls ${ }^{2}$

A calf fed on milk from a bracken fed cow showed evidence of severe immunosuppression ${ }^{26}$

Mice fed on spores developed significantly more mammary tumours than controls ${ }^{8}$ and also more gastric tumours and leukaemia. ${ }^{17}$ Ingestion of fresh spores, not dried, was associated with gastric tumours

Approximately one third of the offspring of mice who had ingested milk from bracken fed cows developed pulmonary tumours and/or mammary tumours. This suggests that a carcinogen may have passed to the offspring during gestation or lactation in their mothers ${ }^{25}$

increased temperature has been shown to increase bracken growth. ${ }^{5}$ Estimates of bracken encroachment in the UK vary from an increase of $2 \%$ per annum in upland grasslands ${ }^{6}$ to reports of a natural decline in some places. ${ }^{7}$ Some types of land are most at risk of increased bracken or bracken encroachment because of climate change (Wales, south west and upland margins of northern England) and/or changing land use (Wales, Pennines and western Scotland).

Bracken produces spores of approximately

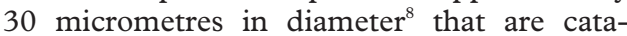
pulted into the air between mid-August and mid-to-late September. ${ }^{9}$ Spore yield varies from year to year. ${ }^{10} \mathrm{~A}$ number of years with few or no spores being produced will be followed by a year with exceptionally high spore yield (a mast year). Mast years tend to occur when the weather from May to July is particularly sunny, dry, and hot. ${ }^{11}$ Spores can be transported over long distances by the wind ${ }^{12}$ but most spores fall within a few metres of the source. Low concentrations of bracken spores were found ${ }^{9}$ in the airstream over Edinburgh even though the nearest small area of bracken was $1.6 \mathrm{~km}$ away. It is likely that spores are present in some concentration in the air everywhere in Britain during the sporing season. Bracken spores have been found to contain a carcinogen. ${ }^{13}$

Positive and negative attributes of bracken have been pointed out.

Negative aspects include: toxicity to animals-acute poisoning, cancers, and tick diseases; loss of grazing/farming land ${ }^{14}$; conservation-loss of wildlife habitat, invasion of Sites of Special Scientific Interest; forestrysuppression of young tree growth; shootingbracken competes with heather, needed as habitat for grouse; possible effects on health human from consumption of the plant or contaminated milk or water; ingestion of spores, via the link with sheep ticks and Lyme disease.

Positive aspects of bracken are: it is an attractive plant in the countryside; it can be used for controlling access to land as a physical barrier; it is a useful habitat for some flora and fauna; it can be a useful compost to replace peat. ${ }^{15}$

\section{Effects on animal health}

Bracken carcinogenicity in animals was first demonstrated in $1965 .{ }^{16}$ Subsequent studies (in the field and laboratory) have associated the ingestion of bracken (or its extracts) with diseases and cancers of many sites in many animal species. Rats, guinea pigs, sheep, cattle, hamsters, quails, toads have all developed tumours after the ingestion of bracken or its extracts. ${ }^{17}$ Table 2 illustrates some of the animal diseases that have been associated with the consumption of bracken or its extracts.

\section{Possible toxic agents in bracken}

Crude bracken extracts have been found to be positive in the Ames mutagenicity assay but only after bioactivation with liver microsomal systems. ${ }^{27}$ Several agents within bracken have been investigated for evidence of carcinogenesis, including quercetin, shikimic acid, and ptaquiloside. The toxic constituents have not been unequivocally identified. Studies ${ }^{28}{ }^{29}$ are being carried out to determine the chemical nature of the toxin. These studies have revealed that many of the constituents of bracken have low cytotoxic activity and therefore are not directly linked to the aetiology of acute fern poisoning. The International Agency for Research into Cancer (IARC) reported in the late 1980s that, although there is sufficient evidence for the carcinogenicity of bracken in animals, there is inadequate evidence for it to be regarded as a human carcinogen. ${ }^{30}$

Ptaquiloside is a toxin isolated from bracken, which has been described as almost certainly the major carcinogen in bracken fern by Smith and Seawright. ${ }^{31}$ The Dutch Expert Committee on Occupational Standards ${ }^{32}$ state that ptaquiloside is or should be considered as carcinogenic to humans. As ptaquiloside can be potentially transferred to humans via milk, it is necessary to monitor the grazing habits of dairy herds. Japanese workers have looked at the clastogenic effects of ptaquiloside and conclude that the carcinogenic potency may result from these clastogenic effects. The spectrum of DNA damage caused by ptaquiloside resembles that of classic alkylating agents. ${ }^{33}$

Shikimic acid and Cyclohexane carboxylate (a metabolite of shikimic acid) show little evidence of carcinogenicity from animal studies and inadequate evidence for carcinogenicity in humans. They are not mutagenic in the Ames assay. Although shikimic acid is unlikely to be a carcinogenic initiating agent, it may act as a carcinogen promoting agent in the bracken fern. ${ }^{34}$

Quercetin has been found to be nongenotoxic and is not thought to play a part in the carcinogenicity of the bracken fern. ${ }^{35}$

Povey et $a l^{36}$ administered bracken spores and bracken extracts to mice to investigate whether such exposure leads to the formation of DNA adducts. DNA isolated from the upper intestinal tract and liver was digested to 3' nucleosides. Adducts were extracted and analysed using documented methods. Bracken induced DNA adducts were detected and it may be possible to apply these methods to determine human exposure. These studies also 

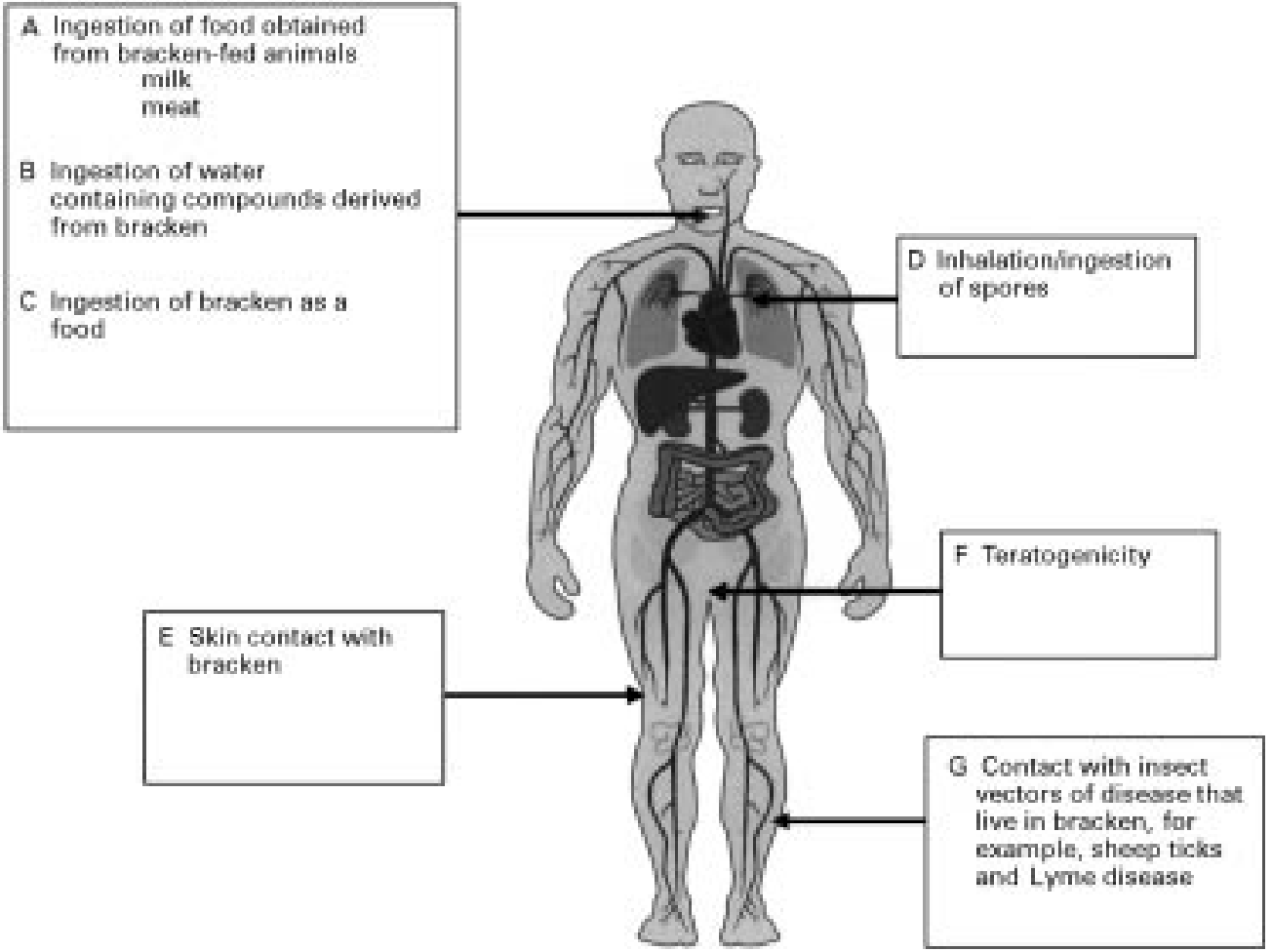

Figure 1 Possible pathways between humans and bracken.

showed that DNA reactive compounds were released slowly from spores. These bracken induced DNA adducts may have arisen from ptaquiloside and their formation may result in the carcinogenic action of ptaquiloside. As with all biological monitoring techniques, it is necessary to synthesise the putative carcinogens before it is possible to definitively identify their mode of action.

Boiling bracken fronds in alkaline conditions seems to render them less harmful, presumably by inactivating some of the toxic agent(s). The Japanese boil fronds in water and soda ash, this process would reduce the carcinogenicity before eating. ${ }^{37}$

\section{Possible pathways of bracken through humans}

Figure 1 shows theoretical pathways between bracken and humans.

FOOD

Bracken is not traditionally part of the British diet, but in Japan and some areas of South America the fronds are eaten. ${ }^{38}$ Bracken rhizomes were a traditional food of Maori and Aborigines. ${ }^{39}$ Some observational studies have found an association between consumption of bracken and human stomach and oesophageal cancers. Daily intake of bracken in Japan was associated with increased risk of oesophageal cancer (2.1-fold in men and 3.7-fold in women). ${ }^{40}$ The risk of eating meat from animals fed on bracken is unstudied and unknown.

MILK

Ptaquiloside has been found in milk from bracken fed cows ${ }^{41}$ and drinking such milk has been associated with cancers in animals. ${ }^{25}$

However, it is thought that dilution resulting from the bulk processing of milk would make any risk from milk in the UK quite remote. This route of exposure may be more relevant in small, geographically remote rural communities, such as parts of Costa Rica. ${ }^{42}$

\section{WATER}

There is no evidence that water contaminated by bracken causes human disease despite the fact that it has been shown that some toxic compounds in bracken are water soluble and therefore could possibly leach into water sources. ${ }^{43}$

INHALATION AND INGESTION OF SPORES As spores have been found to be carcinogenic in mice, ${ }^{17}$ there is a theoretical risk that inhalation and subsequent ingestion could be carcinogenic in humans. There have been no studies of the effects of exposure of animals to airborne spores, only direct ingestion of spores. The study by Povey et $a l^{36}$ shows that, in mice, spores administered by gavage produce DNA adducts. The significance of these adducts needs further investigation.

SKIN

There have been no studies of the effects of bracken on humans or animals resulting from direct skin contact. This route would seem an unlikely cause of disease.

\section{TERATOGENICITY}

There is some evidence that mice whose mothers had been fed milk from bracken fed cows developed more pulmonary and mammary tumours than controls. ${ }^{25}$ 
INSECT VECTORS OF DISEASE

Bracken is an important habitat for sheep ticks (Ixodes ricinus) in the UK, which are the major vector for Lyme disease caused by Borrelia burgdorferi. ${ }^{44}$

\section{Studies on human health}

Much of the speculation about harmful effects of bracken on human health is based on its effects in animals. However, studies exploring the relation between bracken and human health have concentrated on stomach and oesophageal cancer. Stomach cancer incidence is highest in Japan, Central and South America. Within the United Kingdom, the highest incidence is in North Wales. Incidence is also higher in the north than the south and in western areas compared with eastern areas of Britain. Other risk factors associated with gastric cancer include blood group A, atrophic gastritis and, pernicious anaemia, cigarette smoking, dietary factors (such as spicy foods and nitrate consumption), and lower social class. It appears to be commoner in coal miners and some chemical workers. ${ }^{45}$ Residents from areas with a high incidence of stomach cancer seem to maintain this risk after migration, but their children do not, suggesting an environmental factor in the aetiology. Like many cancers, stomach cancer is probably multifactorial.

In common with many environmental exposures, bracken exposure is very difficult to measure. Studies estimate exposure using: past or present residence or occupation in a bracken rich area; recall of past or recent buttermilk consumption in a bracken rich area; history of eating bracken. The few studies looking directly at associations between bracken and human disease are discussed below.

A case-control study was prompted by the high incidence of gastric cancer in North Wales. ${ }^{46}$ It was part of a larger study of gastric cancer. A questionnaire elicited intake of various foods, particularly those containing retinol, salt, $\beta$ carotene, and vitamin C. ${ }^{47}$ No clear hypothesis regarding bracken formed part of the study's aims. One hundred and one histologically confirmed gastric cancer cases were compared with 77 cancer controls and 202 non-cancer controls. All patients were residents of Gwynedd, Wales and were recruited from three local hospitals. Controls were not eating any special diet, nor were they suspected of having peptic ulceration. Cases and controls were matched for age, sex, and social class. The 101 cases represented just over one third of all suspected cases of stomach cancer, the others were excluded because of an incorrect diagnosis, lack of histology, being too unwell, refusing participation, being missed or because of dietary reasons. Non-cancer controls were inpatients with acute and chronic medical and surgical illnesses. Questions relevant to bracken included the amount of bracken in the vicinity of their childhood home; consumption of non-mains water; duration of residence in Gwynedd (20 year bands); own and father's occupation (farmer, quarryman or other); buttermilk consumption as a child and adult. A statistically significant increased relative risk
KEY POINTS

- Bracken is carcinogenic in many animal species.

- Humans may be exposed to bracken by the inhalation and subsequent ingestion of bracken spores.

- Measuring human exposure to bracken is difficult-in the future monitoring of bracken induced DNA adducts may be helpful in determining exposure.

- There is no confirmed association between exposure to bracken and human disease.

- The possibility of a risk to human health from bracken warrants further research, perhaps focusing on outdoor workers.

was found when comparing exposure versus non-exposure to bracken as a child (relative risk 2.34 compared with non-cancer controls and 2.09 compared with cancer controls). Comparing buttermilk consumption during adulthood to its non-consumption gave a relative risk of 1.86 for the non-cancer controls and 2.67 for the cancer controls. There was also a significant increase in risk with longer residence in Gwynedd. It is possible that living near bracken as a child, drinking buttermilk, and living in Gwynedd act as a proxy for rural life, or some other exposure relevant to gastric cancer. Selection, recall, and observer bias were all potential problems of this study and the methods and analysis are difficult to follow. The study appears not to consider cigarette smoking or other known risk factors for stomach cancer.

Buckley et al compared standardised mortality ratios and incidence rates (1974-1988) for stomach and oesophageal cancer from the cancer registry for the 34 districts in Gwynedd to 1968 survey maps of bracken, deep and shallow peat and areas with non-mains water supply. ${ }^{48}$ There was no apparent hypothesis, but the study assumed that these factors may be associated with stomach cancer. No spatial correlation was found. Multiple regression analysis considering only rural districts and combining all carcinogen sources found some statistically significant correlations that are difficult to interpret as the analyses are poorly described. The authors concluded that there existed a positive correlation between bracken and stomach cancer for men and women and with oesophageal cancer for men alone. The study did not seem to take account of how long the cases had lived in the area assigned to them or to analyse confounding factors such as smoking or social class.

A large prospective study in Japan found that eating bracken significantly increased the risk of oesophageal cancer, but only when combined with drinking hot gruel tea (chagayu). ${ }^{40}$

Age specific incidence rates of cervical, gastric, and oesophageal cancers in people born in bracken infested and bracken free areas in Costa Rica were compared by VillalobosSalazar et $a l_{.}^{42}$ Incidence data were extracted from the National Cancer Registry. "Bracken- 
infested" and "bracken-free" were defined according to height above sea level, a method validated in a previous study. The authors did not present any tests of statistical significance but reported that the age standardised incidence of gastric and oesophageal cancer in women and all persons born in bracken infested areas were at least twice that of those born in bracken free areas.

No studies of the health effects of bracken on forestry and other outdoor workers regularly occupationally exposed to inhalation and ingestion of bracken spores appear to have been performed.

\section{Assessing the evidence}

Using the so called "criteria for causality" 49 the quality of the evidence of an association between bracken and human cancer can be explored.

Strength of association - a strong association between a factor and a disease is less likely to occur by chance or error than a weak one. In animals, the strength of association between bracken consumption and cancers is high, but in humans the strength of association is approximately double that of controls. ${ }^{42} 46$

Consistency upon repetition - this refers to whether the same results have been found by different persons, in different circumstances and at different times. Many animal studies have confirmed the role of bracken in producing various diseases and cancers. For bracken spore carcinogenicity, two studies have found spores to be carcinogenic in mice. ${ }^{8}{ }^{17}$ Natural experiments of human populations in Gwynedd and Costa Rica found consistent resultsthat living in a bracken infested area may be associated with increased gastric cancer by some mechanism. ${ }^{42}{ }^{46}$

Temporal relation - a risk factor must occur before the onset of disease if it is a causal agent. The onset of tumours is often difficult to define. Studies of the association between human health and bracken have not been prospective and could not therefore establish a temporal relation.

Biological gradient - this refers to a dose response relation, where the greater the level of a risk factor that a subject is exposed to, the higher is the likelihood of them contracting the disease. Of the human studies, only the Japanese study was large enough to assess the dose response relation. It was found that among hot gruel tea drinkers a dose response relation existed between the frequency of bracken consumption and the risk of oesophageal cancer. The risk was highest in those eating bracken daily, lowest in those who ate it rarely or never did so, and intermediate in those eating bracken occasionally. ${ }^{40}$

Plausibility - there should be a plausible biological explanation between the risk factor and the disease. The animal evidence of cancers caused by bracken certainly makes the same association in humans biologically plausible. Also some tumours in mice are similar histologically to human tumours.

Coherence with explanation - the association should not conflict with what is known about the natural history and biology of the disease. The evidence about bracken and health does not conflict with what is known about oesophageal and gastric cancer in humans. However, it is accepted that gastric cancers are likely to be multifactorial and therefore bracken (even if causally associated) may be only one of many contributory causes. Gastric cancers also occur in areas where bracken is sparse.

Experimental evidence - natural experiments may give clues to whether an association is causal. Remote areas where people live an isolated life among the bracken and drink milk from bracken fed cattle could provide a type of natural experiment, but with no local control group.

Analogy - the association between bracken exposure and human cancer would be strengthened if there was already a different plant exposure known to be causally associated with a human cancer.

\section{Conclusion}

Bracken, a ubiquitous plant, is toxic to many animals species. It affects a high percentage of animals that are tested and affects many organ systems. There is however no tumour in animals that is pathognomic of bracken exposure. It is not possible to extrapolate from animal models to humans.

Establishing whether the plant constitutes a risk to human health is extremely difficult. There are problems in the measurement of exposure to this environmental agent. Moreover, seeking to establish exposure through history taking risks bias caused by selective recall. Published data in human populations consist of two analytical ${ }^{4046}$ and two observational studies, ${ }^{42}{ }^{48}$ most of which fail to comment on confounding risk factors for gastric or oesophageal cancer or to describe their methods and analyses sufficiently. Only two of these studies are relevant to exposure in the United Kingdom, ${ }^{46}{ }^{48}$ where eating bracken is extremely rare and milk processing on a large scale is likely to dilute any toxins in milk.

The only one of eight traditional criteria for causality that is adequately fulfilled is that of biological plausibility.

When considering the possible harmful properties of bracken, distinguishing between the concepts of hazard and risk is useful. A hazard is a set of circumstances that may have harmful consequences; risk is the probability of harmful consequences occurring from a hazard. ${ }^{50}$ For example, lightning is a hazard, but the risk of being struck by lightning is very small, approximately one in ten million. ${ }^{51}$ Bracken may be a hazard to humans, but, as yet, there is no convincing evidence that people are at serious risk from it. The capacity of the plant to destroy productive farmland and limit human food supply may be a more serious risk for health in some countries, than any theoretical risk of carcinogenesis. ${ }^{14}$

The people most at risk from any bracken hazard are people who work or play among bracken, especially in the sporing season and in some countries, people who eat bracken or drink milk from bracken fed cows. If the groups 
most exposed to bracken in the United Kingdom could be defined, this could offer further research opportunities.

The possibility of a risk to human health from bracken warrants further research, especially in light of the plant's apparent increase. Analytical studies, using a carefully considered measure of bracken exposure are required to clarify this risk. A case-control study of gastric cancer would be the next logical step.

Conflicts of interest: none.

Funding: none.

1 Yorkshire Evening Post. Curse of the killer bracken. Leeds: 4 July 1996.

2 Countryfile. BBC1, 28 August 1994

3 The Bracken Advisory Commission. Bracken: the risks. Marlborough: The Bracken Advisory Commission, 1996.

4 Taylor JA. The bracken problem: a global perspective. In Thomson JA, Smith RT, eds. Bracken biology and management. Sydney: Australian Institute of Agric

5 Werkman BR, Callaghan TV. Bracken growth in a changing environment. In: Smith RA, Taylor JA, eds. Bracken: an environmental issue. Leeds: International Bracken Group, special publication no 2, 1995:90-3

6 Hopkins A, Wainwright J, Murray PJ, et al. 1986 survey of upland grassland in England and Wales: changes in age structure and botanical composition since 1970-82 in relation to grassland management and physical features. Grass tion to grassland management and

7 and Forage Science 1988;43:185-98.

(Pteridium aquilinum). In: Thomson JA, Smith RT, eds. (Pteridium aquilinum). In: Thomson JA, Smith RT, eds.
Bracken biology and management. Sydney: Australian Institute of Agricultural Science, occasional publication no 40, 1990:63-9.

8 Villalobos-Salzar J, Mora J, Meneses A, et al. The carcinogenic effects of bracken spores. In: Smith RA, Taylor JA, eds. Bracken: an environmental issue. Leeds: International Bracken Group, special publication no 2, 1995:102-3

9 Cautlon E, Keddie S, Dyer AF. The incidence of airborne spores of bracken, Pteridium aquilinum(L.) kuhn in the rooftop airstream over Edinburgh, Scotland, UK. In: Smith RA, Taylor JA, eds. Bracken: an environmental issue. Leeds: International Bracken Group, special publication no 2, 1995:82-9.

10 Page CN. Taxonomic evaluation of the fern genus Pteridium and its active evolutionary state. In: Thomson PA, Smith RT, eds. Bracken biology and management. Sydney: Australian Institute of Agricultural Science, occaSydney: Australian Institute of Agricul

11 Kendall A, Page CN, Taylor JA. Linkages between bracken sporulation rates and weather and climate in Britain. In Smith RA, Taylor JA, eds. Bracken: an environmental issue. Leeds: International Bracken Group, special publication no 2, 1995:77-81

12 Dyer AF. Does bracken spread by spores? In: Thomson JA, Smith RT, eds. Bracken biology and management. Sydney: Australian Institute of Agricultural Science, occasional publication no 40, 1990:35-42.

13 Evans IA. The carcinogenic, mutagenic and teratogenicity of bracken. In: Smith RT, Taylor JA, eds. Bracken, ecology,
land-use and control technology. Carnforth: Parthenon Publishing Group, 1986:139-46.

14 Hamilton LJ, Tolhurst KG, Waller E. The distribution, abundance and economic impact of bracken (Pteridium aesculentum) in Victoria. In: Thomson JA, Smith RT, eds. Bracken biology and management. Sydney: Australian Institute of Agricultural Science, occasional publication no Institute of Agricult

15 Pitman R. Bracken compost: a substitute for peat? In: Smith RA, Taylor JA, eds. Bracken: an environmental issue. Leeds: International Bracken Group, special publication no 2, 1995:191-6.

16 Evans IA, Mason J. Carcinogenic activity of bracken. Nature 1965;208:913-14.

17 Evans IA. Bracken carcinogenicity. Rev Environ Health 1987;7:161-99.

18 Evans WC. Bracken thiamine-mediated neurotoxic syndromes. Botanical Fournal of the Linnean Society 1976;73 113-31.

19 Rosenberger G. Nature, manifestations, causes and control of chronic enzootic haematuria in cattle. Veterinary Medical Review 1971;2:189-206.

20 Pamukcu A, Goksoy SK, Price MJ. Urinary bladder neoplasms induced by feeding bracken fern (Pteridium aquilina) to cows. Cancer Res 1967;27:917.

21 Bringuier PP, Piaton E, Berger N, et al. Bracken ferninduced bladder tumours in guinea pigs - a model for induced bladder tumours in guinea pigs - a m
human neoplasia. Am $\mathcal{F}$ Pathol 1995;147:858-68.

22 Hirono I, Ito M, Yagyu S, et al. Reproduction of progressive retinal degeneration (bright blindness) in sheep by admin- istration of ptaquiloside contained in bracken. F Vet Med Sci 993;55:979-83.

23 Jarrett WFH, McNeill PE, Grimshaw WTR, et al. High incidence area of cattle cancer with a possible interaction between an environmental carcinogen and a papilloma virus. Nature 1978;274:215-17.

24 Campo MS, Jarrett WFH, Barron R, et al. Association of bovine papillomavirus and bracken fern with bladder cancer in cattle. Cancer Res 1992;52:6898-904.

25 Villalobos-Salzar J, Meneses A, Salas J. Carcinogenic effects in mice of milk from cows fed on bracken fern Pteridium aquilinum. In: Thomson JA, Smith RT, eds. Bracken biology and management. Sydney: Australian Institute of Agricultural Science, occasional publication no 40, 1990:247-51.

26 Evans IA, Jones RS, Mainwaring-Burton R. Passage of Evans IA, Jones RS, Mainwaring-Burton R. Passage
bracken fern toxicity in milk. Nature 1972:237:107-8.

27 White RD, Krumnerman PH, Cheeke PR, et al. An evaluation of acetone extracts from six plants in the Ames mutagenicity test. Toxicol Lett 1983;15:135-6.

28 Ngomou AJ, Jones RS. Genotoxicity studies of quercetin and shikimate in vivo in the bone marrow of mice and gas-
tric mucosal cells of rats. Vet Hum Toxicol 1996;38:176-80.

9 Ngomou AJ, Jones RS. Cytotoxicity studies of quercetin, shikimate, cyclohexane carboxylate and ptaquiloside. Vet Hum Toxicol 1996;38:14-18.

30 International Agency for Research into Cancer (IARC). Bracken Fern (Group 2B). IARC Monogr Eval Carcinog Risk Chem Hum 1987:(suppl 7):135-6.

31 Smith BL, Seawright AA. Bracken fern (Pteridium sp.) carcinogenicity and human health - a brief review. Natural Toxins 1995;3:1-5.

32 Dutch Expert Committee on Occupational Standards. Scientific documentation on the Dutch list of occupational carcinogens (II). Bracken fern: kaempferol, ptaquiloside, quercetin and shikimic acid. Den Haag Ministry of Social Affairs and Employment, 1995:14-23.

33 Saffhill R, Margison GP, O’Connor PJ. Mechanisms of carinogenesis induced by alkylating agents. Biochim Biophys Acta 1985;823:114-16

34 Jones RS, Ali M, Ioannides C, et al. The metabolic and cell transforming properties of shikimic acid and some of its bacterial and mammalian metabolites. Toxicol Lett 1983;19: 43-50.

35 Van der Hoeven JC. Occurrence and detection of natural mutagens and modifying factors in food products. Princess Takamatsu Symp 1985;16:119-37.

36 Povey AC, Potter D, O'Connor PJ. Post-labelling analysis of DNA adducts formed in the upper gastrointestinal tissue of mice fed bracken extract or bracken spores. $\mathrm{Br} \mathcal{F}$ Cancer mice fed bracken

37 Hirono I, Shibuya C, Shimizu M, et al. Carcinogenic activity of processed bracken used as a human food. $\mathscr{f}$ Natl Cancer Inst 1972;48:1245-50.

38 Hirono I. Edible plants containing naturally occurring carcinogens in Japan. Fpn f Cancer Res 1993;84:997-1006. 39 Veitch B. Aspects of Aboriginal use and manipulation of bracken fern. Hamilton LJ, Tolhurst KG, Waller E. The distribution, abundance and economic impact of bracken (Pteridium aesculentum) in Victoria. In: Thomson JA, Smith ian Institute of Agricultural Science, occasional publication no 40, 1990:215-26.

40 Hirayama T. Diet and cancer. Nutr Cancer 1979;1:67-81.

41 Alonso-Amelot ME, Castillo U, Smith BL, et al. Bracken ptaquiloside in milk. Nature 1996;382:587.

42 Villalobos-Salzar J, Meneses A, Rojas JL, et al. Bracken derived carcinogens as affecting animal and human health in Costa Rica. In: Taylor JA, ed. Bracken toxicity and carcinogenicity as related to animal and human health. cation, University College North Wales, 1989:40-51.

43 Evans IA, Al-Samarrai AMH, Smith RMM. Bracken toxicity, identification of some water soluble compounds from crozier and rhizome. Res Vet Sci 1984;37:261-5.

44 Sheaves BJ, Brown RW. A zoonosis as a health hazard in UK moorland recreational areas: a case study of Lyme disease. fournal of Environmental Planning and Management 1994; 38:201-14.

45 Doll R, Peto R. Epidemiology of cancer 4.101 and 4.118. In: Oxford textbook of medicine. 2nd ed. Oxford: Oxford University Press, 1987:101-4

46 Galpin OP, Whitaker CJ, Whitaker RL, et al. Gastric cancer in Gwynedd: possible links with bracken. Br f Cancer 1990; 61:737-40.

47 Galpin O, Whitaker C. Stomach cancer, retinol and bracken is there a connection? In: Taylor JA, ed. Bracken toxicity and carcinogenicity as related to animal and human health. Aberystwyth: International Bracken Group Special Publication, University College North Wales, 1989:52-7.

48 Buckley L. Bracken, gastric cancer and the Gwynedd population. In: Taylor JA, ed. Bracken toxicity and carcinogenicity as related to animal and human health. Aberystwyth: International Bracken Group Special Publication, University College North Wales, 1989:58-79.

49 Hill AB. Principles of medical statistics. 9th ed. London: Lancet, 1971:313.

50 Calman KC. Cancer: science and the communication of risk. BM7 1996;313:799-802

51 British Medical Association. The BMA guide to living with risk. Harmondsworth: Penguin, 1990. 